Original Research

\title{
The Effect of Thinking Like a Nurse Simulation as an Online Clinical Learning Method on Nursing Students' Satisfaction and Confidence during the COVID-19 Pandemic
}

\section{Dian Fitria, Jehan Puspasari and Puspita Hanggit Lestari}

STIKes RS Husada, Jakarta, Indonesia

\begin{abstract}
Introduction: Corona Virus Disease (Covid-19) was declared as a pandemic by the World Health Organization (WHO) resulting in changes in existing patterns of life. This impact also affects the world of education, including nursing vocational education. Nursing vocational education must be able to design online methods for the clinical competency with existing facilities and infrastructure. The online clinical method can describe the achievements achievable in clinical facilities so as to build students' satisfaction and confidence.
\end{abstract}

Methods: This research used quasi-experimental pre-posttest without control group method by providing clinical learning thinking like a nurse simulation. The research sample consists of 110 diploma students with purposive sampling method. Simulation focuses on clinical judgment, communication skills, and skill simulations by adopting clinical practice in hospitals. Assessment is measured using Simulation Design Scale (SDS) and Student Satisfaction and Self-Confidence in Learning Scale (SCLS). Pair t test with level of significance 0.05 is used to process data.

Results: It is found that there is an increase in students' satisfaction and confidence using the clinical simulation method of "thinking like a nurse" having an average $40.69 \%$. Meanwhile, online clinical learning methods has an average increase of $114 \%$. There is an effect of thinking like a nurse simulation method on students' satisfaction and self-confidence $(\mathrm{p}<0.05)$.

Conclusion: This research is recommended to add to the reference for online nursing clinical learning methods during Covid-19. Determining the ratio between students and lecturers in online clinic learning can be considered for further research.

\section{ARTICLE HISTORY}

Received: March 16, 2021

Accepted: July 06, 2021

\section{KEYWORDS}

covid-19; online clinical learning; nursing student

\section{CONTACT}

Dian Fitria

$\square$ dianfitriafanani@gmail.com
STIKes RS Husada, Jakarta,
Indonesia

Cite this as: Fitria, D., Puspasari, J., \& Lestari, P. H. (2021). The Effect of Thinking Like a Nurse Simulation as an Online Clinical Learning Method on Nursing Students' Satisfaction and Confidence during the Covid-19 Pandemic. Jurnal Ners, 16(2). 111-118. doi:http://dx.doi.org/10.20473/in.v16i2.25701

\section{INTRODUCTION}

The determination of the status of Covid-19 spread as a pandemic on 11 March 11 by the World Health Organization (WHO) resulted in all learning activities turned online. The Decree of the Minister of Education and Culture through a circular number 4 of 2020 gave an order to carry out the learning and teaching process from home starting from 24 March, 2020 to reduce the acceleration of the spread of the Covid-19 virus.

All educational institutions were forced to adapt very quickly. The learning and teaching process from home had to be carried out immediately to achieve the students' competencies. Simple online methods, such as through chat, voice record, video record, online meeting applications, email, to learning via web were specially designed by educational institutions. All institutions thought hard to be able to provide effective online learning for their students, including educational institutions with diploma nursing program (Al-Balas et al., 2020).

Educational institutions can no longer send students to gain learning experiences through clinical practices since the emergence of Covid-19. However, the closure of these educational practices cannot stop the teaching and learning process. It is not easy to transform learning at clinical institutions into an 
online effort, so preparation is required to design appropriate methods so that clinical learning outcomes in knowledge and skills can still be achieved (De Metz \& Bezuidenhout, 2018)

The three main competencies obtained from learning methods at clinical institutions are the ability of students to carry out clinical judgments, communication skills, and nursing procedure skills. Learning methods that are carried out online must be done through very well-made simulations so that they are representative to achieve nursing knowledge and clinical judgment (Letcher, Roth, \& Varenhorst, 2017). Clinical judgment is the key to caring and decision-making for intervention on patients based on existing assessments and data, (Yuan, Williams, \& Man, 2014), and reduced evidence-based experience in conducting clinical judgment can cause students to lack critical skills in nursing process and real problem solving for patients (Konrad, Fitzgerald, \& Deckers, 2020a).

Online clinical learning has been carried out and evaluated in clinical courses in the even semester $2019 / 2020$. The method used is to provide cases, group discussion, online case presentations, and videos on nursing action procedures. This method is not sufficiently representative of students who do not acquire experience doing clinical judgment, communication skills, and nursing procedure skills. Unrepresentative methods of learning have an impact on students' satisfaction and self-confidence. Some issues that make online learning dissatisfied are less time to practice procedural skills, numerous tasks, insufficient group discussions, technical learning, and network problems (Shih, Chen, Chen, \& Wey, 2013a). Dissatisfaction may produce anxiety in students and cause them to doubt their abilities, causing further impact, namely from decreased academic achievement to student retention (Abdous, 2019). Confidence is very important for all individuals since it affects the performance of the work done and the results of the work. Therefore, it is very important to build nurses' confidence with effective online learning methods so that they have satisfaction with the clinical learning process that is carried out online.

Based on this description, the researchers develop a "thinking like a nurse" method adapted and modified based on the clinical judgment for the nurse learning model (Tanner, 2006). The process shall have three main stages to train skills in conducting clinical judgment, namely noticing, interpreting and response, and reflection. (Tanner, 2006). Noticing is the first stage; the lecturers provide simple cases and students are trained to complete the assessment and the necessary supporting data, as if the student met a new patient at the hospital. In this phase, the students are triggered to think critically about the data that must be studied, diagnostic data on supporting patients, and a flow of thinking on the reason why the data are needed to be completed. The interpreting stage is the stage where students are able to interpret the data obtained through the noticing stage; making diagnosis and designing the interventions to be carried out and knowing the rationality of implementing these interventions. The responding stage is carried out where students evaluate the actions taken. In this method, researchers include the process of communication and nursing procedure skills while students will be trained to think critically in overcoming patient problems according to their developmental conditions; besides that, students will also be trained to carry out activities in the nursing room such as handover, Situation, Background, Assessment, Recommendation (SBAR), preconference, and post-conference. A self-reflection process carried out in the learning process will help students understand learning outcomes; the reflection process carried out will also increase professional development, personal growth, empowerment, and facilitated learning This research is expected to produce appropriate online clinical learning methods and to increase students' satisfaction and confidence. The result of this study can be used as a reference for online nursing clinical learning methods during Covid-19.

\section{MATERIALS AND METHODS}

The method used in this study is a "quasi-experimental pre-posttest without control group" using statistical tests with paired t-test. The sampling technique uses a nonprobability sampling with a purposive sampling method with a sample size of 110 students with the inclusion criteria of students who attended mental and maternity clinical lectures with a supervisor who is a member of the research team and the sampling process was carried out for five days for each class with lectures fully accompanied for two sessions and two session student group discussions. Independent variable in this research is online clinical method. The Simulation Design Scale (SDS) instrument by Jeffries and Rizzolo (2006) with Cronbach's alpha 0.96 was used to assess the method using questionnaires assessed using a Likert scale of 1-5. The dependent variable of this research is satisfaction and self-confidence. The instrument used, namely the questionnaire, is the Student Satisfaction SelfConfidence in Learning Scale (SCLS) by Jeffries and Rizzolo (2006) with a Cronbach's alpha value of 0.94 . The satisfaction assessment component consists of satisfaction on the learning method, the variety of materials provided, the facilities in the processes of learning, motivation, and suitability of the simulation process with the competencies to be achieved (Jeffries \& Rizzolo, 2006). In measuring satisfaction and selfconfidence, the researchers use the concept put forward by Jeffries and Rizzolo (2006). Self-confidence is assessed through the aspects of mastery of the material provided, the need for the material presented, the availability of learning resources, and a place to look for learning sources, both sources for questions and sources of reference.

The first stage of research implementation is to conduct a literature study and identification of research problems. The second stage is a pre-test to measure the level of satisfaction and self-confidence and an assessment of the design of the simulation method used 
Table 1. Stages of Implementing Online "Thinking Like Nurse” Clinical Learning Method

\begin{tabular}{lll}
\hline \multicolumn{1}{c}{ Stages } & \multicolumn{1}{c}{ Lecturers' Activities } & \multicolumn{1}{c}{ Students' Activities } \\
\hline Explanation of & Explains the clinical learning process using the “Thinking & \\
learning methods & like a nurse” simulation \\
\hline Clinical Judgment: & Determination work schedule groups - morning and
\end{tabular}

Clinicaljudgment:

Noticing

(Days 1-3)

\section{evening}

Shares medical records (simulations) and formulas to use

Divides trigger cases (cases will be provided on the first day and changes in the patient's condition will be given on the following day until the patient is discharged).

Patients are treated for 3 days

Day 1-Simulation: asks questions

1. Which follow-up studies should be done?

2. Why are they done?

3. What diagnostic tests should be done?

4. What is the purpose of the examination?

Day 2- the simulation provides the progress of the case.

Simulation with questions:

1. What causes the change in the patient's condition?

2. Describe any further assessments to carry out

Day 3 - simulated patient preparation for discharge.

1. What are the discharge preparations made by the nurse for the patient?

2. What is the rationale for such preparation?

3. What forms should the nurse prepare?

Clinical Judgment: Interpreting (Days 2 and 3)
Have discussion on the cases

acquired

Pre-conference

Hand over

Fills in the assessment; Fills in the Initial patient's assesment form to the ward (day 1)

Carries out further assessment (day 2)

Prepares the patient to return home (day 3)

Performs self-reflection
Simulation: through questions

1. What are the characteristic limitations of the diagnosis offered?

2. Which is the priority problem?

Simulation: through questions

1. Why are there such planning and outcome criteria?
Simulation (discussion on zoomeeting)

Clinical Judgment: Responding

(Days 2 and 3) taken by students
1. Lecturers provide the results of nursing actions

2. The lecturer provides an overview of the patient's condition after the intervention

3. The Lecture provide advices for student about Nursing care delivered, SBAR hand over, and documentation.
Enforcing Nursing Diagnosis

Performs self-reflection

Making plans and criteria for nursing care outcomes Performs self-reflection

1. Carrying out the actions to be performed in accordance with the action documentation planning on the documentation sheet.

2. Situation, Background, Assesment, Recommendation (SBAR) exercise

3. Communications

4. Performs self-reflection

5. Creating documentation of nursing actions

6. Filling out the Integrated patient progress notes form (documentation)

7. Handover exercise Making plans and criteria for next nursing care outcomes

1. What Should you do if the next condition of patient ......? (lecture explain progress patient condition)

2. Which your next priority implementation for patient?

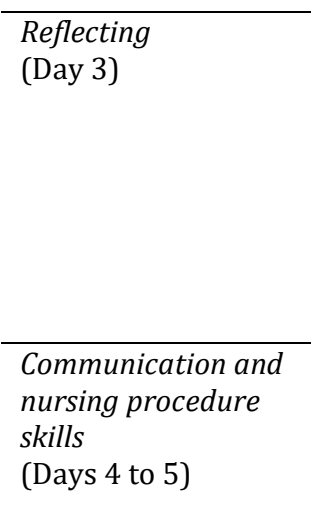

Simulation (discussion on zoomeeting)

Lecture Motivates self-reflection by asking question about students understand learning outcomes; the reflection process carried out.

Simulation: through questions

1. What the lesson learnt today?

2. How the feeling?

3. What the learning outcone you can get today?

4. What should you improve for your self?

Provides nursing procedures that will be trained in accordance with the agreement on the discussion of responding implementation divide nurse-patient
1. Self-reflection (while treating patients from admission to discharge)

2. post-conference

Making Self Reflection
1. Creates patient-nurse scenarios for cases that have been created for 3 days.

2. Performs self-reflection 
by students who have participated in online clinical learning without the "thinking like a nurse" method followed by the provision of the "thinking like a nurse" simulation method and the third stage carries out a posttest to measure the level of satisfaction and selfconfidence of students and an assessment of "thinking like a nurse" learning method with the activities as provided in Table 1 - stages of implementing online the "thinking like a nurse" clinical learning method.

This study has passed the ethical test by the Health Research Ethics Commission of the Faculty of Nursing, the Airlangga University, number 2118KEPK. Data were collected through questionnaires and did not cause any harm to the respondents. Ethical requirements and respondent rights have been fulfilled throughout the research process.

\section{RESULTS}

The results of satisfaction and self-confidence assessment (Table 2) show that the mean value before the intervention is 37.28 with a median value of 27.50. Meanwhile, the mean satisfaction and selfconfidence of respondents after the intervention is 52.45 with a median value of 52 . The table above also illustrates that there is a difference of 15.17 in the mean before and after intervention with a mean increase of $40.69 \%$. Hence, it can be concluded that there is a difference in the mean and an increase in the mean of the respondents' satisfaction and confidence before the intervention and after the intervention.

Based on table 3, it is found that the mean of the respondents' online clinical learning method before the intervention is 37.58 with a median value of 27.50. Meanwhile, the mean of clinical learning method by respondents after intervention is 80.46 with a median value of 80 . Hence, it can be concluded that there is a difference in the average online clinical learning method before the intervention and after the intervention. The table above also illustrates that there is a difference of 52.9 in the mean before and after with a mean increase of $114 \%$. Hence, it can be concluded that there is a difference in the mean and an increase in the mean of the respondents' satisfaction and confidence before the intervention and after the intervention.

In examining the effect of providing online clinical learning methods with the "thinking like a nurse" method, it was found the students' average satisfaction and self-confidence before and after the effect of providing online clinical learning methods with the "thinking like a nurse" method on students' satisfaction and self-confidence is 15.16, and the difference between these differences is between

Table 2. Average Satisfaction and Confidence Before and After the Intervention $(\mathrm{N}=110)$

\begin{tabular}{|c|c|c|c|c|c|c|c|}
\hline Variables & Mean & Median & SD & Min-Max & $\begin{array}{c}\text { Mean } \\
\text { Difference }\end{array}$ & $95 \% \mathrm{CI}$ & $\begin{array}{c}\text { Average increase } \\
\text { percentage }(\%)\end{array}$ \\
\hline $\begin{array}{l}\text { Satisfaction and } \\
\text { Confidence before } \\
\text { Intervention }\end{array}$ & 37.28 & 27.50 & 12.3 & $26-52$ & 15.17 & $0.41-0.59$ & 40.69 \\
\hline $\begin{array}{l}\text { Satisfaction and } \\
\text { Confidence after } \\
\text { Intervention }\end{array}$ & 52.45 & 52.00 & 5.2 & $38-65$ & & $0.62-0.80$ & \\
\hline
\end{tabular}

Table 3. Average Online Clinical Learning Methods Before and After Intervention (N=110)

\begin{tabular}{lccccccc}
\hline \multicolumn{1}{c}{ Variables } & Mean & Median & SD & Min-Max & $\begin{array}{c}\text { Mean } \\
\text { Difference }\end{array}$ & $\mathbf{9 5 \%}$ CI & $\begin{array}{c}\text { Average increase } \\
\text { percentage }\end{array}$ \\
\hline $\begin{array}{l}\text { Online Clinical } \\
\text { Learning Methods } \\
\text { before }\end{array}$ & 37.58 & 27.50 & 12.8 & $26-52$ & & $0.38-0.57$ & 114 \\
$\begin{array}{l}\text { Intervention } \\
\text { Online Clinical }\end{array}$ & 80.47 & 80 & 6.7 & $61-100$ & & & \\
$\begin{array}{l}\text { Learning Methods } \\
\text { after Intervention }\end{array}$ & & & & & & & \\
\cline { 1 - 1 }
\end{tabular}

Table 4. The effect of providing Online Clinical Learning Methods with "thinking like a nurse" Method on Students' Satisfaction and Self-confidence $(\mathrm{N}=110)$

\begin{tabular}{lcccccc}
\multicolumn{1}{c}{ Variables } & Mean & SD & SE & \multicolumn{2}{c}{ 95\% CI } & P Value \\
\cline { 4 - 6 } & & & & Lower & Upper & \\
\hline $\begin{array}{l}\text { Respondents' satisfaction and confidence before } \\
\text { and after the intervention }\end{array}$ & 15.16 & 13.07 & 1.246 & 12.70 & 17.63 & $<0.000$ \\
\hline
\end{tabular}

Table 5 .The Effect of Giving the "thinking like a nurse" Simulation Method on Online Clinical Learning Methods $(\mathrm{N}=110)$

\begin{tabular}{lcccccc}
\multicolumn{1}{c}{ Variables } & Mean & SD & SE & \multicolumn{2}{c}{ 95\% CI } & P Value \\
\cline { 4 - 6 } & & & & Lower & Upper & \\
\hline $\begin{array}{l}\text { Respondents' online learning methods before } \\
\text { and after the intervention }\end{array}$ & 42.9 & 14.03 & 1.345 & 40.24 & 45.54 & $<0.000$ \\
\hline
\end{tabular}


17.63 and $12.70(95 \%$ confidence interval of the lower and upper differences), Sig (2-tailed) of $<0.000$. Hence, it can be concluded that there is a mean difference in students' satisfaction and confidence between before and after the "thinking like a nurse" simulation; therefore, there is an effect of the "thinking like a nurse" simulation method on students' satisfaction and self-confidence.

Based on Table 5, the results show that the average online clinical learning method for students before and after the "thinking like a nurse" simulation is 42.9 , and the difference between these differences is between 45.54 and 40.24 (95\% confidence interval of the lower and upper differences), Sig (2-tailed) of $<0.000$. Hence, it can be concluded that there is an average difference between the online clinical learning method for students before and after the "thinking like a nurse" simulation; therefore, there is an effect of the "thinking like a nurse" simulation method on the online clinical learning method.

\section{DISCUSSION}

The "thinking like a nurse" method is a design adapted from Tanner (2006) and Konrad, Fitzgerald, and Deckers (2020). The stages of this online method are divided into three, namely Clinical Judgment, Communication, and Procedure Skills Simulation. This method is designed since, based on Adam (2015), the clinical online learning method must cover three cognitive aspects (knowledge, comprehension, critical thinking), psychomotor (skill development), and affective (emotional \& behavioral response) (Adams, 2015). This method is designed as an effort to respond to the Covid-19 pandemic which makes nursing students unable to practice in hospitals. For the first semester during the Covid-19 pandemic and before the application of this clinical method, online clinical activities were carried out with case provision in which students were asked to produce preliminary reports on three-day nursing care and presentation of the case and continuing with cases' question and answer sessions. Through the method, students only reached satisfaction and confidence with a mean of 37.28 with a mean value of the online clinical learning method used before the intervention of 37.58. The interaction of the old method is less interaction between lecturer and student, and the method cannot describe the situation in the hospital.

Student satisfaction and confidence are low due to the learning process, which is not optimal for presenting clinical learning experiences conducted online. The procedure performed is still oriented toward training students to be able to provide nursing care; but is not yet at the application of simulation stage and, with this method, students only gain knowledge without any clinical learning experiences such as communicating with patients or simulating nursing actions. This is in line with the results of research conducted by Al-Balas et al. (2020) saying that the clinical medical practice method during a pandemic must include three aspects, namely knowledge, nursing care practice, and representative experience in caring for patients performed online by simulating nursing actions (AlBalas et al., 2020). The results of research by McGann et al. (2020) state that the online clinical method will be effective if it is not only in the form of knowledge on nursing care, but when it is followed by providing feedback on simulated procedures, providing videos, and practicing communication with patients, and by so doing can increase self-confidence of the students (McGann et al., 2020).

Another study states that students' dissatisfaction in learning is due to anxiety on seven things felt by students, namely unclear online learning technique mechanisms, the absence of face-to-face session, high risk of distraction to social media during online learning, minimum feedback, unsupportive online learning environment, and the absence of interaction with friends such as in the classroom (Abdous, 2019). The research results of Chen et al. (2013) show several issues that cause dissatisfaction in online learning, i.e., less time to practice procedural skills, abundance of tasks, insufficient group discussions, technical learning, and network problems (Shih et al., 2013b). In the previous method, students only work on the given cases, make a path of flow, and ask and answer questions on nursing care provided; students could not see changes in the patients' condition such as students caring for patients in the ward.

After the intervention using the "thinking like a nurse" method adapted and modified from Tanner (2006) and Konrad, Fitzgerald, and Deckers (2020) in five days as an online clinical learning method, the average students' satisfaction and confidence increase to 52.45 with an increase of $40.69 \%$ from the condition before the intervention (Konrad et al., 2020a; Tanner, 2006). Likewise, the mean value for the online clinical learning method used after the intervention is 80.47 ; this value increases $114 \%$ from the previous method. This is because the "thinking like a nurse" method provides students with experiences on caring for patients, but it is done online. The noticing stage is the first stage in the clinical judgment process. Lecturers provide simple cases and students are trained to complete the assessment and the necessary supporting data, as if the student met a new patient at the hospital. In this phase, the students are triggered to think critically about the data that must be studied, diagnostic data on supporting patients, and a flow of thinking on the reason why the data are needed to be completed. The management of trigger cases by students is the key to optimal online learning processes (Konrad et al., 2020b; Kyrkjebø, 2006). Learning feedback is immediately provided by the lecturer after students complete the data to know whether the assessment data really needs to be studied before the students make diagnosis. The lecturer also provides the results of the assessment completed on the patient. The focus of the first day on this assessment provides clarity to students on the competencies in nursing assessment 
skills. This is consistent with a research from Kim et. al. (2020) that giving the right feedback will increase students' confidence during online learning.

The interpreting stage is the stage where students are able to interpret the data obtained through the noticing stage, making diagnosis and designing the interventions to be carried out and knowing the rationality of implementing these interventions. Lecturers discuss the rationality of diagnosis and planning. In the third stage, the responding stage is carried out where students evaluate the actions taken. The three stages of clinical judgment, namely noticing, interpreting, and responding, are carried out by the interaction of lecturers and students for three days and performed in stages. In each learning process, the lecturer provides feedbacks and triggers for students to think critically. Through this method, students know whether each stage of the nursing care that they make is appropriate or not, and know the rationale for each action. Feedback obtained after each process is the interaction between students and lecturers; this can increase satisfaction and the method becomes more effective because one of the reasons for dissatisfaction with online learning is the lack of interaction with lecturers and students (D'Aquila, Wang, \& Mattia, 2019; De Metz \& Bezuidenhout, 2018; Singh et al., 2021)

The nursing care given every day is made based on the development or changes in the patient's condition provided by the lecturer as a trigger for nursing care for the next day. Therefore, students are continuously trained to think critically in designing nursing care such as in clinical practice. This is in accordance with the good learning components according to Jeffries and Rizollo (2006), including competence (objectives, material preparation, trigger cases), support (learning resources; motivation provided by the lecturer), problem solving (opportunities to ask questions, ease of finding sources to solve problems), feedback (providing constructive feedback, and selfreflection processes), and accuracy (accuracy with real life conditions) (Jeffries \& Rizzolo, 2006). This method is also a student-centered clinical learning method that can increase student satisfaction and confidence when the process is able to motivate, the presence of lecturers for interaction and collaboration with students, clear learning activities, and students understand the right goals, competencies, and deadlines (Tartavulea, Albu, Albu, Petre, \& Dieaconescu Silvia, 2020).

In the second stage of the "thinking like a nurse" method after clinical judgment, namely communication skills, students will be trained to do handover and patient process reports to doctors using SBAR either during handover or on the phone. Students practice handover with other students for managed cases. The supervisor observes the handover process carried out by the students; the components mentioned are the completeness of the data being transferred and the next action to be taken. Input is also provided by peers between groups. This stage is carried out because, according to O'Neil,
Fisher, Rietschel, and Fisher (2018), three principles that must be fulfilled in online learning are easy to access, easy to navigate, and easy to interact with others. It is also stated that communication is the core of online learning because it is with this communication that interactions will be built between students and students, student and lecturers, and students with trigger cases on learning (O’Neil, Fisher, Rietschel, \& Fisher, 2018). Increasing interaction and communication in learning will increase discipline, independent learning ability, selfmotivation, level of participation, time management and being active in learning (Reinckens, Philipsen, \& Murray, 2014).

The third stage consists of students performing peer-to-peer simulation and practicing selected actions for one of the diagnoses. This action is performed online by students. Actions taken to be simulated are assessment, education, or independent nursing actions. The simulation of providing education to fellow students with the patient nurse scenario is the most effective online clinical action simulation method (Rodríguez, Navarro, Pino, \& Maroto, 2020). Simulations of nursing actions with scenarios that are played online are parts of the student-centered learning method and are able to increase students' satisfaction and self-confidence (Englund, Olofsson, \& Price, 2017). In this stage, the lecturer also provides videos of nursing procedures that are not possible to be performed by online role play. All actions taken are documented in a simulated medical record prepared and designed in accordance with the standards of teaching hospitals commonly used as practice venues.

These three stages produce average increase in students' satisfaction and confidence. In this clinical learning method, students are motivated to carry out nursing care according to the patient's development, perform communication for nurse-nurse and nursepatient, and are trained to foster a sense of caring and empathy in caring for patients. Soundy et al. (2021) state that there are three aspects that students must be trained in in order to increase self-confidence in caring for patients, namely the experience of patient nurse interaction, patient empowerment, and training in caring and empathy (Soundy et al., 2021). The same thing is revealed in the study that selfconfidence in learning is influenced by eight factors, namely mastery or understanding of certain materials or expertise, materials according to needs, increased psychomotor abilities, availability of reference sources, and the ability to solve existing problems (Franklin, Burns, \& Lee, 2014). Clear and continuous feedback can increase satisfaction and self-confidence so that individuals will be able to perform cognitive functions to seek efforts to move closer to goals through various ways and be able to set specific goals for themselves with self-regulation abilities (Luthans, 2007).

Every day, at the end of an online work meeting, students reflect themselves on clinical learning activities. It is designed to increase students' 
satisfaction and confidence. The self-reflection process carried out in the learning process will help students understand learning outcomes; it will also increase professional development, personal growth, empowerment, and facilitated learning (Langley \& Brown, 2010). Good understanding of learning outcomes by students through self-reflection prevents them from experiencing helplessness, burnout, and burdens (Suliman, Abu-Moghli, Khalaf, Zumot, \& Nabolsi, 2021). This learning method also enhances the role of the lecturers as facilitator; the lecturers are in charge of not only providing trigger cases, but also listening to the results of solving cases by students on the last day. In this method, the lecturers understand and participate in online clinical learning interactions. This becomes one of the reasons for students' satisfaction and confidence since they know where to ask and are trained to think critically. Schroeder, Shogren, and Terras (2020) state that online students need instructors to provide personal presence, by being engaging, approachable, understandable, patient, and passionate about the subject. This method does not only focus on students processing cases with a nursing care approach, but also on the interaction between lecturers and students (Schroeder, Shogren, \& Terras, 2020). The limitation of this research is that it hasn't considered yet the ratio of students and lecturers based on the ratio on clinical setting; nevertheless, the number of students is divided into several small groups in team teaching.

\section{CONCLUSION}

Based on this research, it can be concluded that the provision of the online clinical learning method of "thinking like a nurse" has an influence on students' satisfaction and self-confidence. This method is designed with the urgency of the impact of Covid-19 causing students to be unable to do clinical practices in hospitals. This design provides a student clinical learning experience, such as learning in a hospital, where students manage patients through nursing care for five days until the patient is discharged. This design is also developed for students to maintain communication skills and nursing procedures, as well as interactions between patient-nurses and nursespeers. From this method, they learnt three aspects that students must be trained in in order to increase self-confidence in caring for patients, namely the experience of patient nurse interaction, patient empowerment, and training in caring and empathy (Soundy et al., 2021). This method is designed to achieve the clinical online learning method criteria which must cover three cognitive aspects (knowledge, comprehension, critical thinking), psychomotor (skill development), and affective (emotional \& behavioral response) (Adams, 2015).

This research is expected to be able to provide a reference contribution to nursing vocational education to develop online clinical learning methods. This method is also expected to be adopted by nursing vocational education institutions in achieving clinical learning competence. The "thinking like a nurse" method can anticipate changes in hospital practice regulations that have re-accepted students in a limited number, so that it can be used as blended learning. This method also needs to be re-developed by taking into account the number of students and the number of lecturers to get a more optimal process. This research is recommended to determine the ratio between students and lecturers in online clinic learning and can be considered for further research.

\section{REFERENCES}

Abdous, M. (2019). Influence of satisfaction and preparedness on online students' feelings of anxiety. Internet and Higher Education, 41(January), 34-44. https://doi.org/10.1016/j.iheduc.2019.01.001

Al-Balas, M., Al-Balas, H. I., Jaber, H. M., Obeidat, K., AlBalas, H., Aborajooh, E. A., ... Al-Balas, B. (2020). Correction to: Distance learning in clinical medical education amid COVID-19 pandemic in Jordan: current situation, challenges, and perspectives (BMC Medical Education, (2020), 20, 1, (341), 10.1186/s12909-020-02257-4). BMC Medical Education, 20(1), 1-8. https://doi.org/10.1186/s12909-020-02428-3

D'Aquila, J.M., Wang, D. and Mattia, A. (2019). Are instructor generated YouTube videos effective in accounting classes? A study of student performance, engagement,motivation, and perception. Journal of Accounting Education, 47, pp.63-74.

De Metz, N., \& Bezuidenhout, A. (2018). An importance-competence analysis of the roles and competencies of e-tutors at an open distance learning institution. Australasian Journal of Educational Technology, 34(5), 27-43. https://doi.org/10.14742/ajet.3364

Englund, C., Olofsson, A. D., \& Price, L. (2017). Teaching with technology in higher education: understanding conceptual change and development in practice. Higher Education Research and Development, 36(1), 73-87. https://doi.org/10.1080/07294360.2016.11713 00

Franklin, A. E., Burns, P., \& Lee, C. S. (2014). Nurse Education Today Psychometric testing on the NLN Student Satisfaction and Self-Con fi dence in Learning , Simulation Design Scale, and Educational Practices Questionnaire using a sample of pre-licensure novice nurses. YNEDT, 34(10), 1298-1304. https://doi.org/10.1016/j.nedt.2014.06.011

Jeffries, P.R., Rizzolo, M. A. (2006). Designing and Implementing Models for the Innovative Use of Using Simulation to Teach Nursing Care of Ill Adults and Children: A National, Multi-site, Multimethod Study. National League for Nursing. New York, NY. 
Kim, J. W., Myung, S. J., Yoon, H. B., Moon, S. H., Ryu, H., \& Yim, J. J. (2020). How medical education survives and evolves during COVID-19: Our experience and future direction. PLOS ONE, $15(12$ December), 1-13. https://doi.org/10.1371/journal.pone.0243958

Konrad, S., Fitzgerald, A., \& Deckers, C. (2020a). Nursing fundamentals À supporting clinical competency online during the COVID-19 pandemic. Teaching and Learning in Nursing, 000, 17-20. https://doi.org/10.1016/j.teln.2020.07.005

Konrad, S., Fitzgerald, A., \& Deckers, C. (2020b). Nursing fundamentals À supporting clinical competency online during the COVID-19 pandemic, 000, 17-20. https://doi.org/10.1016/j.teln.2020.07.005

Kyrkjebø, J. M. (2006). Classroom and Clinic : Getting it Wrong and Getting it Right, 45(3).

Langley, M. E., \& Brown, S. T. (2010). Perceptions of the Use of reflective learning journals in online graduate nursing education. Nursing Education Perspectives, 31(1), 12-17. https://doi.org/10.1043/1536-5026-31.1.12

Letcher, D. C., Roth, S. J., \& Varenhorst, L. J. (2017). Simulation-Based Learning: Improving Knowledge and Clinical Judgment Within the NICU, 284-290.

Luthans, Y. \& A. (2007). Psychological Capital: Developing the Human Competitive Edge. Oxford University Press.

McGann, K. C., Melnyk, R., Saba, P., Joseph, J., Glocker, R. J., \& Ghazi, A. (2020). Implementation of an ELearning Academic Elective for Hands-On Basic Surgical Skills to Supplement Medical School Surgical Education. Journal of Surgical Education, 1-11. https://doi.org/10.1016/j.jsurg.2020.11.014

Nancy E. Adams. (2015). Bloom's taxonomy of cognitive learning objectives Nancy. J Med Lib Assoc, 103 (3)(July), 152-153. https://doi.org/DOI: http://dx.doi.org/10.3163/1536-5050.103.3.010

O’Neil, C. A., Fisher, C. A., Rietschel, M. J., \& Fisher, C. A. (2018). Interacting and Communicating Online. Developing Online Learning Environments in Nursing Education, 99-110. https://doi.org/10.1891/9780826199140.0008

Reinckens, J., Philipsen, N., \& Murray, T. L. (2014). Nurse practitioner: Is online learning for you? Journal for Nurse Practitioners, 10(9), 700-705. https://doi.org/10.1016/j.nurpra.2014.07.015

Rodríguez, D. J., Navarro, M. del M. T., Pino, F. P. del, \& Maroto, O. A. (2020). Simulated Nursing Video Consultations: An Innovative Proposal During Covid-19 Confinement. Clinical Simulation in Nursing, (5 august 2020). https://doi.org/10.1016/j.ecns.2020.08.004
Schroeder, S., Shogren, M., \& Terras, K. (2020). Student Connectivity in Online Programs: Role of the Nurse Faculty. Journal for Nurse Practitioners, (xxxx). https://doi.org/10.1016/j.nurpra.2020.09.005

Shih, H., Chen, S. E., Chen, S., \& Wey, S. (2013a). The Relationship Among Tertiary Level EFL Students ' Personality, Online Learning Motivation And Online Learning Satisfaction. Procedia-Social and Behavioral Sciences, 103, 1152-1160. https://doi.org/10.1016/j.sbspro.2013.10.442

Shih, H., Chen, S. E., Chen, S., \& Wey, S. (2013b). The Relationship Among Tertiary Level EFL Students ' Personality, Online Learning Motivation And Online Learning Satisfaction, 103, 1152-1160. https://doi.org/10.1016/j.sbspro.2013.10.442

Singh, H. K., Joshi, A., Malepati, R. N., Najeeb, S., Balakrishna, P., Pannerselvam, N. K., ... Ganne, P. (2021). A Survey of E-Learning Methods in Nursing and Medical Education During COVID-19 Pandemic in India. Nurse Education Today, 99(November 2020), 104796. https://doi.org/10.1016/j.nedt.2021.104796

Soundy, A., Hemmings, L., Gardiner, L., Rosewilliam, S., Heneghan, N. R., Cronin, K., \& Reid, K. (2021). Elearning communication skills training for physiotherapy students: A two phased sequential mixed methods study. Patient Education and Counseling, (xxxx), 1-9. https://doi.org/10.1016/j.pec.2021.01.022

Suliman, W. A., Abu-Moghli, F. A., Khalaf, I., Zumot, A. F., \& Nabolsi, M. (2021). Experiences of nursing students with the unprecedented abrupt online learning forced by the national curfew due to COVID-19: A qualitative research study. Nurse Education Today. https://doi.org/https://doi.org/10.1016/j.nedt.2 021.104829

Tanner CA. (2006). Thinking like a nurse: a researchbased model of clinical judgment in nursing. Journal Nurse Education, June 45(6), 204-211. https://doi.org/10.3928/01484834-2006060104

Tartavulea, C. V., Albu, C. N., Albu, N., Petre, R. I., \& Dieaconescu Silvia. (2020). Online Teaching Practices and the Effectiveness of the Educational Process in the Wake of the COVID-19 Pandemic. Amfiteatru Economic, 22((25)), 920-936. https://doi.org/10.24818/EA/2020/55/920

Yuan, H. Bin, Williams, B. A., \& Man, C. Y. (2014). Nursing students' clinical judgment in highfidelity simulation based learning: A quasiexperimental study. Journal of Nursing Education and Practice, 4(5), 7-15. https://doi.org/10.5430/jnep.v4n5p7 